\title{
THE BODILY OTHER AND EVERYDAY EXPERIENCE OF THE LIVED URBAN WORLD
}

\author{
Oren Bader ${ }^{\mathrm{a}}$ and Aya Peri Bader ${ }^{\mathrm{b}}$
}

aThe Cohn Institute for the History and Philosophy of Science and Ideas, School of Philosophy, Faculty of Humanities, Tel Aviv University, Tel Aviv; bavid Azrieli School of Architecture, Faculty of the Arts, Tel Aviv University, Tel Aviv

\begin{abstract}
This article explores the relationship between the bodily presence of other humans in the lived urban world and the experience of everyday architecture. We suggest, from the perspectives of phenomenology and architecture, that being in the company of others changes the way the built environment appears to subjects, and that this enables us to perform simple daily tasks while still attending to the built environment (to a certain, relatively minimal degree). Our analysis shows that in mundane urban settings attending to the environment involves a unique attentional mode, which does not rely on concentrating on, or appreciating the architectural objects, but rather on social attention and on the subject's kinesthesis in relation to the built environment.
\end{abstract}

\section{ARTICLE HISTORY}

Received 30 December 2015

Accepted 1 August 2016

\section{KEYWORDS}

Architecture; everyday experience; built environment; social attention; Gurwitsch, Schutz

\section{Introduction}

The purpose of this article is to clarify the role of the bodily presence of others in facilitating our everyday experience of the built environment, where, typically, the built objects do not capture our full-focused attention, yet are involved in our daily experience of the urban world.

Alfred Schutz suggests that our world is always already colored by the attitudes of others with whom we interact. ${ }^{1}$ He maintains:

that my attitudes become always less specifically colored by myself, that they always become more typical the more they accommodate those of everyone else, or, so to speak, become always more anonymous. ${ }^{2}$

Schutz's investigations show that other humans, directly and indirectly, influence many of our attitudes and experiences. This is particularly evident in the lived urban world, in which subjects constantly encounter (or expect to encounter) one another. First, the presence of others changes the way the built environment appears to the subject. Second, encountering others in everyday urban settings enables subjects to perform different simple daily routines while still attending to their built surroundings. ${ }^{3}$ 
This suggests that in the urban world built objects are usually not in the center of our attention yet are still part of our attentional field. In what follows, we argue that this unique mode of appearance relies, among other things, on the broadness and the dynamic structure of the human field of attention and on the bodily relation between subject and other. Drawing on phenomenological analyses, mainly on the work of Aron Gurwitsch ${ }^{4}$ and Alfred Schutz, ${ }^{5}$ and on architectural perspectives of the structure of the (built) lived world, we show that the attentional experience of others (actual or potential), along with the subject's sense of their own bodily kinesthesis in relation to their built surroundings, profoundly influences the experience of the everyday built environment.

A phenomenological perspective shows that human attention comprises different modes of noticing. ${ }^{6}$ These modes modulate the subject's perceptual field, ${ }^{7}$ especially where the experience involves others. In everyday urban settings, other subjects are not merely the unnoticed background of what is in the center of our attention, rather their bodily presence influences our experience of the built surroundings. Being in the direct company of others changes the way the urban environment appears to subjects and enables us to attend to more in this environment, while still being preoccupied with our daily routines. For example, the presence of others in the immediate (built) environment diminishes the subject's need to focus on identifying potential hazards or threats. ${ }^{8}$

Others do not only carry our attention in the everyday built surroundings, their bodily presence also influences the construction of our lived urban world. This is particularly evident once other subjects are no longer available to us in our everyday built settings, in which case, the urban environment changes. The absence of others suddenly colors it with uncertainty and uncanniness. I no longer attend to it as a familiar place, and this influences the way it appears to me. This suggests that other subjects play a crucial role in our lived urban world, both in broadening our field of attention and in constituting the everydayness of the built environment.

This suggestion unfolds in this article in the following manner. First, we propose that in everyday urban settings architectural objects do not usually appear in the center of our attention, yet we nevertheless still attend to them. We support our view with Aron Gurwitsch's understanding of the broadness and richness of the human field of attention. Then, drawing on phenomenological perspectives and on empirical studies, we point to the crucial role of social attention in constructing the subject's lived world. Based on Gurwitsch's model and on our understanding of social attention, we then argue that the bodily presence of others is essential for the construction of the subject's everyday experience of the built environment. We support our position with Schutz's analysis of the structure of subjects' direct encounters. Finally, by examining the influence of the absence of others on the experiences of the everyday built environment, we show how other subjects construct the subject's lived urban world.

A quick note regarding our theoretical toolkit; According to our suggestion, social attention, the experience of attending to and with other human subjects, is a special mode of attention, different in feel and in what it enables subjects to do from other types of attention, such as attending to non-human objects. The everyday built environment is regarded herein as the built urban setting(s) in which the subject lives and acts, particularly her daily surroundings such as familiar residential and commercial streets, public squares and boulevards, business districts etc. 


\section{The structure of everyday experience of the built environment}

\subsection{The everydayness of the built world}

In everyday life, the built world usually does not require our (focal) attention. Walking down the street, we may ponder our daily tasks, talk to a friend, or argue over the phone, while still attending (to some extent) to the urban surroundings. These everyday practices are part of the way we experience the built environment as "ordinary" or "mundane." In his essay "The work of art in the age of its technological reproducibility," Walter Benjamin describes this state as one of "distracted reception." Benjamin employs the word 'distraction' to underscore the very essence of the everyday architectural experience, in which, in daily life, without radical changes such as unexpected disturbance, subjects do not usually need to focus on their built surroundings. He suggests that, in mundane situations-in contrast to an encounter with a work of art-architecture is primarily perceived in a state of habitual distraction. ${ }^{10}$ We are familiar with a place and act within it almost without noticing or reflecting on it. This type of experience is far removed from the concentrated attention lavished, for example, upon a unique building. ${ }^{11}$

Importantly, although built objects do not capture our full-focused attention in this state of "distraction," they are involved in constructing our experience of the everyday built world through the dynamic body-place relation. ${ }^{12}$ That is to say, the way built objects appear to us in daily situations is bound up with the subject's kinesthesis in relation to the built environment (and with the bodily presence of other subjects) and is involved in the construction of our sense of everydayness.

In the lived world the body-place relation unfolds, as Maurice Merleau-Ponty suggests, "through the agency of my body... I have the positing of objects through that of my body, or conversely the positing of my body through that of objects.... because my body is a movement towards the world." ${ }^{13}$ Crucially, in urban settings this relation materializes in a special way. That is, the body intertwines with the built objects in a unique manner that stems from, among other things, the presupposition of the subject's movement that is entrenched in the built environment.

More specifically, the urban environment is constructed by humans for the use of humans. Therefore, it already entails (in most cases) the bodily presence and movement of human subjects, as much as it affords them. Whereas natural environments afford the subject certain activities given the kind of body we have, ${ }^{14}$ the (lived) urban world presupposes our body, insofar as it is already designed in accordance with our bodily movements. This kinesthetic pregiveness is crucial for the construction of the subject's experience of the everyday built environment, as it profoundly influences the way built objects are attended and perceived. Notably, the body-place interaction, which is embedded in the urban environment to begin with, allows the construction of experiential properties involved in this mundane experience. In particular, it enables what Casey defines as the mode of bodily motion between places. ${ }^{15}$

In an earlier work one of us, Peri-Bader, uses an applied research method to show that everyday experience of architecture involves distinct spatiotemporal properties, such as light, space, scale, enclosure and flow. ${ }^{16}$ Importantly for our case, these properties are constructed through the subject's movement in relation to the built environment. In other words, the properties that take part in the construction of the everyday experience of the lived urban world originate in the dynamic relationship between the subject and the (built) 
environment. This suggests that the architectural setting is constantly involved in the manifestation of the subject's everydayness, even when it is not present in the center of the subject's attention.

This suggestion is supported by phenomenological and ecological perspectives on the structure of human attention that show that in daily situations our attention to the environment depends on temporality and kinesthesis and involves a dynamic background. ${ }^{17}$ More specifically, in mundane experiences in the built environment, the directly-attended objects, whether they be our cell phone, our friend, or the fancy red car passing by, are always given to us with a background, ${ }^{18}$ which usually consists of architectural objects. These objects, as Benjamin's observation suggests, are barely noticed, yet they appear to us. In urban settings this occurs mainly because we have a pre-reflective awareness of our body in relation to the built objects, an awareness that is influenced by the way urban environments are designed. ${ }^{19}$ For example, the directionality and the size of a sidewalk in a busy business district and its relation to the buildings around it (in terms of scale, spatiality and materiality) presupposes the movement and the activities of its users, as much as it enables them.

The dynamic experiential structure, in which in daily situations architecture is (usually) part of the active attentional background, ${ }^{20}$ rather than the center of the subject's attention, is of great importance for our welfare as it helps prevent the built world from forcing itself on us, demanding our full focal attention. This is crucial for the construction of the everyday experience of the urban environment ${ }^{21}$ as it is involved in the way we enact our attention ${ }^{22}$ and perform simple daily tasks while still attending to the built objects around us. It takes an extraordinary situation or condition, such as a sudden disturbance or a particular fascination, to generate a shift into focalization. ${ }^{23}$ This can occur, for example, when encountering an unexpected hazard or when facing an object that calls for appreciation. ${ }^{24}$ In other words, the everyday experience of the built world involves an active-dynamic attentional structure. Though certain (bottom-up) situations demand that we focus attention on the built surroundings, under ordinary circumstances architecture does not stand in the center of our attentional field, but nonetheless we still attend and experience it.

\subsection{Aron Gurwitsch's model of attention}

Our view of the breadth of the human field of attention in everyday (urban) life is compatible with Gurwitsch's phenomenological model, which suggests that attention includes more than what is (temporally) in the center of attention. Basing his discussion on Husserl's analysis of the subject's different attentional modes, including the "primarily" noticed and the almost unnoticed "secondary," ${ }^{25}$ Gurwitsch holds that attention is not restricted solely to what is directly attended by the subjects. He points out that "we never deal with a theme simpliciter; instead, we confront a theme standing in a field." 26 This suggests that the subject's attention is wider and richer than proposed by psychological accounts, which focus on the subject's attentional limitations. ${ }^{27}$ Gurwitsch maintains that it is wrong to make a distinction between what appears in the center of our focal attention (the spotlighted object) and what is usually regarded (mistakenly) as unnoticed or unselected. He proposes that the "searchlight theory of attention has to be abandoned altogether," 28 proposing instead that (voluntary) attention is organized as a field. This attentional field, which is constantly active and dynamic, depending on the transient location of its center, comprises the center of attention, the thematic field (the context of the attended locus), and its margins. In our 
case, although the built world does not appear in the center of our attention in everyday situations, it is always already part of our (field of) attention since it is placed within it.

Gurwitsch specifically acknowledges the importance of the environment (the built and the natural) in constructing the subject's attention, stressing that the attended object is always located within its environment. This environment, which belongs to the domain of the co-given, does not merely appear to subjects as a non-intruding background (a sort of white screen or "noise"), but rather it is part of their attention, since "it is impossible to perceive a thing without environment." ${ }^{29}$ However, while the built environment, under normal circumstances, is co-given with the attended center, and thus is always part of the subject's attentional field, its relation to the center and its location within this field need further clarification. According to Gurwitsch's view, ${ }^{30}$ not all that is co-given with the theme is directly connected to it. Gurwitsch distinguishes between items that are related to the center of attention and, therefore, determine the subject's attitudes toward it, for example, the shaded colonnade I am crossing while looking at the entrance of the building, and other features in the environment that do not (directly) influence the subject's attitude toward the attended object, such as, the wall behind the table on which my cup of coffee is placed.

The first circle of relatedness to the center of attention is the thematic field. Gurwitsch emphasizes that the theme "is inserted into this framework of senses," which comprises a "set of materially related objects." 31 These objects are organized with reference to the center of attention and have a special relation to it. We suggest that in everyday built environments the thematic field includes material objects as well as spatial properties that influence the subject's everydayness. These properties are involved in the flow of the experience constructing the body-place relation, ${ }^{32}$ such as, the (ever-changing) distance between subjects and the buildings around them, the shadow these buildings (and trees) cast over the sidewalk as I walk on my way to work, the width of this sidewalk and its direction, and so on. ${ }^{33}$

The second attentional circle, namely the periphery (or the margin) of attention, consists of items that were left outside the thematic field, namely items that are connected to the center of attention solely by virtue of being given simultaneously with it. ${ }^{34}$ In my everyday built surroundings these features include, for example, particular architectural details, cars that I pass while walking on the sidewalk, the upper balconies on the buildings near me, the skyscrapers on the other side of the road, and backyards. Importantly, as Gurwitsch's analysis suggests, these features and relations are neither absent from the subject's attention nor are they merely static background for the transient center. Gurwitsch stresses that co-given items, whether they belong to the thematic field or not, are always part of the attentional field ${ }^{35}$ since they take part in forming and preserving it. Thus, attention is not "a matter of obscuring or brightening but is one of organization." ${ }^{36}$

This phenomenological observation helps in elucidating the built world's everydayness, as it suggests that in everyday urban life the subject's attention is organized in a way that includes architecture (at different levels of relatedness to the center), but also prevents that architecture from imposing itself on the subject. In other words, the suggestion that the subject's attention is a dynamic process that relies on organization explains why built objects are part of our attentional field and yet attending to them (though to a lesser degree) does not prevent us from performing simple daily routines at the same time. More specifically, the organization of the attentional field, such as the distance between the subject and the built objects within the field, and the directionality of the subject relative to these objects are involved in maintaining the flow of the lived urban world, which is crucial for establishing 
the subject's everydayness. This suggests that the built features toward which the subject's body is temporally oriented (directly or through the bodily presence of other subjects), is constantly involved in constructing and maintaining the flow of the experience, while other items remain in the periphery since they (as yet) do not directly carry the subject's movements in the lived urban world.

Furthermore, we suggest that, depending on subjects' movements (and as shown next on their orientation toward others in the environment), current marginal items can become part of the new thematic field, and vice versa. For example, I can cross the street to the other side while arguing over the phone, and thus, the built objects that were in the periphery of my attention become my new point of relatedness. In the next section, we suggest that in daily situations in the built environment the construction of the subject's dynamic attentional field usually already involves, and relies on, the bodily presence of other subjects. This extends our attentional field and profoundly influences the way the built environment appears to us. ${ }^{37}$

\section{The influence of the bodily presence of other subjects on the subject's everydayness}

\subsection{Social attention}

In everyday life in the urban world architectural objects usually are not given to me alone, but also to the other people in my environment. This has a profound influence on the way I attend to the built world around me. In mundane situations in the lived urban world, the bodily presence of others is not merely part of the subject's attentional field, but rather the dynamic structure of this field depends, under normal circumstances, on attending to and with other subjects, namely, on social attention. ${ }^{38}$ This suggestion is based on abundant studies from fields such as phenomenology, developmental psychology, and cognitive science that show that attending to and with other subjects plays a part in constructing the subject's lived world. ${ }^{39}$

Fairly early in life, infants already exhibit distinct propensities to detect and follow social cues embedded in other subjects' bodies, such as potential threats, opportunities for cooperation, and interesting features to be explored. ${ }^{40}$ The primary bias to attend to other humans gradually develops, through infant-caregiver dyadic attentional engagements, ${ }^{41}$ into the triadic form of joint attention. ${ }^{42}$ This social capacity enables the subject, when jointly attending with others, to gain their perspectives toward the attended locus, through their gestures, gaze, movements, and posture. Notably, this crucial capacity influences the development of more refined intersubjective traits, such as the capacity to cooperate with others and to understand their mental states. ${ }^{43}$ Furthermore, during infancy the infant develops a distinct inclination, which is bound up with social attention, towards social referencing, i.e., following cues from other people in the environment (particularly their caregivers), about which actions to take. ${ }^{44}$

The importance of social attention for subjects' development and welfare is also shown by cognitive research that reveals that in everyday life attending to and with other human subjects provides the subject with important experiential and informational advantages. For example, by attending to, and with others I can understand their intentions in reaching for an object ${ }^{45}$ or in pointing to a specific location. I can share their perspectives by following their gaze and their posture, ${ }^{46}$ and I can synchronize my movements, emotions and experiences with theirs when attending to the same environment. ${ }^{47}$ Furthermore, a 
growing body of evidence suggests that the subject's attention to others' bodies is based on specific neuronal mechanisms designed to recognize and process social information. ${ }^{48}$ This encourages subjects to rely on others as a source of information regarding the shared world, ${ }^{49}$ and diminishes their reliance on their own, more limited, attentional resources.

\subsection{The bodily other and the lived environment}

The empirical resources that suggest that social attention is involved in constructing the subject's everydayness are in line with phenomenological views that show that in the lived world, the bodily presence of others profoundly influences my experiences, attitudes and perspectives toward it. Husserl suggests that when living with others in the social world I take part in their lives, and vice versa. As he puts it "but in living with one another [Miteinanderleben] each one can take part in the life of the others." ${ }^{\circ}$ Others do not only grant the subject important informational and experiential advantages, but importantly, as Zahavi suggests, ${ }^{51}$ it is through their bodily presence that the world is first experienced by the subject as objective and as real. ${ }^{52}$ In other words, it is only insofar as the other subject appears to subjects as a differentiated other that the world opens up for them as a world already inhabited, therefore communal and objective, and this constitutes inter-subjectivity in its bodily sense.

Schutz's analysis of the structure of the social world shows that when encountering other subjects in my environment I already attend to them as social agents who share my world, through whom I can obtain valuable knowledge about our common environment, and with whom I can share experiences and coordinate activities. ${ }^{53}$ Schutz emphasizes that the other person whom I can directly experience is the one who shares with me community of space and time: "when his experience is flowing side by side with mine [...] When I can at any moment look over and grasp his thoughts as they come into being [...] Persons [are] thus in reach of each other's direct experience." ${ }^{54} \mathrm{He}$ maintains that when living with others I can "directly experience them and their subjective experiences." ${ }^{55}$ This often occurs through their bodily presence in my immediate environment: "the spatial immediacy of the other in virtue of which his body is present to me as a field of expression for his subjective experiences." 56 The social quality that emanates from the (bodily) presence of my fellow humans enables subjects to coordinate activities and perspectives with one another. As Gurwitsch points out, when directly encountering others, "we interlock and interlink our intentions, designs and activities with theirs in thoroughgoing mutuality and interplay." 57

Additionally, and crucially for our discussion, my relation to the other's body is essentially different from my relation to natural objects. As Sartre suggests, ${ }^{58}$ the other's body "is revealed to me as a tool possessing the property of knowing." 59 That is, unlike the built objects, other subjects, like me, are provided with sense organs, therefore, their bodies appear to me as a point of view "on which I can take a point of view." They are uniquely given to me "as an immediate existence," as "a pure in itself." 60 Importantly for the case of the urban world, the other's body always already appears to me in a situation; I grasp it in the context of contingency. Consequently, the future movements of other subjects as well as the organization of objects in relation to their active bodies (actual or as a possibility) is given to me when they appear in my field of attention in everyday situations.

This suggests that when living and operating together in a common world I am constantly attuned to, and rely on, the perspectives embedded in the bodies of the other subjects whom 
I directly encounter. ${ }^{61}$ Therefore, my attentional field in everyday situations in the lived urban world involves others in a way that is different from my attention to non-human objects.

\subsection{The bodily other and the subject's attentional field}

This last suggestion brings us back to Gurwitsch. As Gurwitsch's model suggests, in everyday life the human attentional field includes different items that are given to subjects in different degrees of relatedness. In mundane situations, this field also comprises other subjects in the environment. ${ }^{62}$ These others can be in the center of the subject's focal attention, for example, my colleague to whom I talk when walking together to the office; they can be part of the subject's thematic field, such as the person who walks on the sidewalk beside me when I contemplate my daily tasks; and they can be in the periphery of my attentional field, for example the subjects walking on the other side of the street.

Evidently, as the research on social attention suggests, these others already appear to the subject with their perspectives and attitudes toward the environment as embedded in their bodily kinesthesis and facial expressions. ${ }^{63}$ This has a profound influence on the construction of subjects' relation to the built environment. Whether they appear in the center of attention, in my thematic field, or in the periphery of my attentional field, the perspectives of other subjects toward the daily urban environment (in different degree of relatedness) are available to me when they are part of my attentional field. Moreover, even before we have encountered each other, I am already predisposed to rely on their behavior as social referencing of events in my surroundings. ${ }^{64}$ This suggests that the bodily presence of others in my immediate everyday environment (such as, a street, a public square, or my gym) reduces my need to concentrate attention on the built world around, and this influences my experience of my mundane urban surroundings.

Notably, these others appear to me in different degrees of intensity in accordance with my relation to them and with their temporal location within my field of attention. Schutz's analysis clarifies this suggestion, emphasizing:

The partner, for instance, may be experienced with different degrees of immediacy, different degrees of intensity or different degrees of intimacy. Or he may be experienced from different points of view; he may appear within the center of attention or its periphery... ${ }^{65}$

This shows that the perspectives of others toward the built environment that we share are always available to me when directly encountering them, even when they are not in the center of attention. For example, when walking in my everyday urban world, the space between the buildings that I pass and my body usually includes other subjects. These others (even if not directly attended) are not merely the static background of the built world around me, but rather their bodily presence helps in carrying the flow of my everydayness. First, in this case, my attention already includes (and relies on) their attitudes and perspectives toward the built environment. Second, their bodily presence helps me in sensing the built objects I pass, for example, in utilizing the distance between them and me, and in (better) defining my location within the environment. This suggests that directly encountering others in the everyday environment reduces my dependency on my own attentional resources. In their presence, I no longer need to depend solely on my attentional relation to the built objects around me, which enables me to attend to other daily matters as well. 
The same holds for the presence of others in the periphery of my attentional field. Even though in this case they are not directly involved in my attentional relation to the built objects in my immediate environment, their perspective toward the urban settings is available to me (to a lesser degree), since they are part of my field of attention. This broadens my attention to the built environment and signals for me its everydayness. ${ }^{66}$ In other words, by virtue of the bodily presence of others I can experience built objects in the periphery of my attention as part of my mundane world so that I do not need to pay direct attention to these objects. This suggests that in daily situations the built world usually appears to the subject with two attentional layers: a first person layer, which is my direct attention toward the environment, and a second person layer, namely the perspectives of other subjects in my attentional field toward this environment. Moreover, I can directly attain the perspectives of other subjects, as in the case when they appear in my attentional field, or indirectly, through other subjects in my field who attend to them.

This extended attentional organization enables the everydayness of the built environment, as it prevents the built world from forcing itself on subjects in daily situations, yet allowing them still to attend to it (though in a less demanding way). Consequently, though I do not need to focus attention on architecture in everyday life, my attentional relation to architectural objects in my immediate environment allows me to carry out different simple daily routines as I move through and attend to my urban surroundings. This understanding is compatible with Gurwitsch's notion that shows that attention is primarily a matter of organization. ${ }^{67}$

The experience of the everyday built environment that involves and depends on other subjects is far removed from a situation in which I attend to familiar urban settings in mundane circumstances in the absence of others, such as when jogging early in the morning on my daily path. Although in these situations I also do not (usually) need to concentrate attention on architectural objects, I, nevertheless rely solely on my bodily knowledge, namely on my embodied familiarity with the environment. This changes the way the lived urban world appears to me compared to the experience of everyday built surroundings in the presence of others. More specifically, we suggest that, without others to help in regulating my attention, my attentional field tapers, the city loses its depth, and my attention is vulnerable to external interruptions, such as unexpected sounds and movements.

\section{The influence of bodily others on the subject's everyday built environment}

The suggestion that the everydayness of the built environment rests largely on the bodily presence of other human subjects in our attentional field is supported by an examination of the influence of the absence of others on the subject's lived urban world. In ordinary circumstances, the presence of other subjects in our daily urban surroundings does not surprise us. We usually anticipate finding ourselves in their presence; their company is essential for our welfare and contributes to our familiar sense of a place ${ }^{68}$ This is particularly evident when others are no longer available to the subject in the everyday built world, such as, when walking late at night through a business district that is busy in the daytime. In these situations, the subject immediately focuses attention on the (newly) uncanny surroundings, the built context, and its characteristics, which are now colored with unfamiliarity, strangeness and uncertainty. 
More specifically, when other subjects are absent from my everyday environment I can no longer rely on their perspectives, which are given to me when they are part of my attentional field. Additionally, I immediately lose the unique sense of their bodily presence. Consequently, the built environment penetrates into the center of my attention, while the periphery of my field of attention dissolves. Furthermore, since in this case I can no longer anticipate the moment to come through the bodily kinesthesis of others in my surroundings the enactive flow of time is disturbed, ${ }^{69}$ and the stream of my experience is intruded upon by the built world around me. In other words, when other subjects are absent from my everyday built world, the structure of my attentional field is changed and the everydayness collapses. The built world that was until now barely noticed suddenly discloses itself to me in new ways; by now I no longer recognize it as my everyday familiar built environment, but rather I experience it as different and eerie.

We find a good illustration of our suggestion in the opening scene of the AmericanSpanish movie Vanilla Sky. ${ }^{70}$ The lead protagonist, David Aames (Tom Cruise), wakes up and drives to work through Manhattan's streets in his black Ferrari. The streets are empty; David looks at his watch: the time is 9:00 AM. Through his reaction, we realize that it should have been an ordinary midweek morning in the big city, but the urban surrounding is clearly different than usual. He continues to drive through a chain of empty urban spaces. As the music rises, David reaches Times Square; this most recognized of all commercial intersections, known for its crowded, dense appearance, is now motionless and silent. With not a single person in sight, David pulls over randomly, exits the car, and leaves it in the middle of the street. He begins to walk, faster, then runs, searching in vain for humanity (Figure 1). As this is no longer a familiar everyday environment for him, it fails to offer a stable, comforting and comprehended space. In the absence of others, the built objects around rapidly close in on him, violently penetrating into the center of his attentional field. By now, the built environment appears to him in its massive intimidating features. This

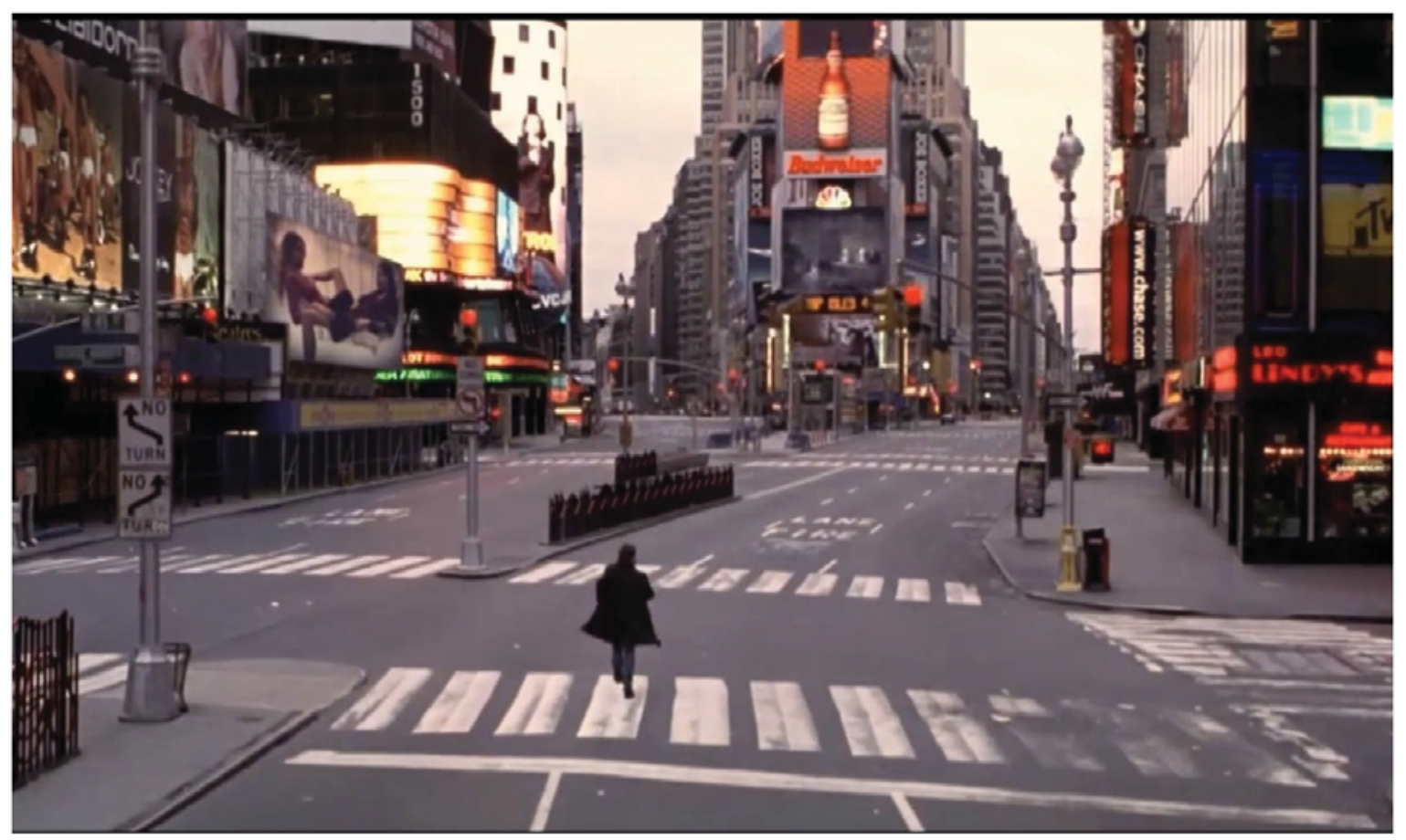

Figure 1. Still from Vanilla sky (Cameron Crowe, 2001), Paramount Pictures. 
situation is somewhat similar to a situation where I walk back home late at night (or very early in the morning) through a usually hectic street. The vibrant street is now empty, not a person in sight. In these circumstances the familiar environment significantly changes. In the absence of others, I focus attention on features that normally I barely notice, such as the entrances to the buildings that I pass and the benches on the sidewalk. Though, given the late hour, I expected to find myself alone in the street, nevertheless the environment forces itself on me, penetrating into the center of my attentional field, while the periphery dissolves, as it does for David.

These examples demonstrate the profound influence of the bodily presence of others on the subject's lived urban world. In daily life, other people's movement, facial expressions and bodily gestures are essential for constructing the everydayness of the built environment. The immediacy of their bodies, their relation to the built surroundings, and their rhythm, speed and directionality, enable me to capture the scale of the environment, its proportions, spatiality and edge, and to pre-reflectively apprehend my opportunities to act within it. For example, the bodily presence of others in my immediate environment allows me to recognize the optional available directions, helps in keeping me from running into obstacles, and prevents the built world from forcing itself on me. When others are no longer available to me in the lived urban world, I lose the crucial advantages that their bodily presence enables, and the everydayness of the built environment dissolves. In these situations, the built environment appears to me as different; it is now an unfamiliar, narrow and strange place for me. With no one to carry my attention and verify the world for me, I need to focus on the built objects surrounding me, and thus I can no longer perform other tasks. This suggests that my everyday urban world presupposes the presence and movements of others, as much as it presupposes mine. When others are absent from my everyday built surroundings, even in circumstances where I anticipated finding myself alone, the built objects, which usually appear in the periphery of my attentional field, capture my full focused attention. In this case, my field of attention narrows down to what directly appears in its center, and this significantly changes the way the urban world is given to me.

\section{Concluding remarks}

In everyday life, under normal circumstances, built objects do not appear in the center of our attention, yet we attend to them (though to a lesser degree). This attentional experience is different from the way we attend to exceptional architecture, such as outstanding buildings, theaters and places of historical significance. Based on phenomenological and architectural considerations we have shown that the scaffolding upon which the everyday experience of the built environment is constructed involves the attentional relation of the subject's enactive body to the built world and the bodily presence of other subjects in our immediate everyday surroundings.

Following in the footsteps of Gurwitsch, ${ }^{71}$ our analysis suggests that in daily situations in the lived urban world the enactive and wide structure of the subject's attentional field influences the way subjects experience architecture as mundane. In everyday urban settings, along with my attention to the built environment, I also regularly attain the perspectives and attitudes of others in this environment, to whom I attend. This broadens my attentional field in the sense that I do not need to focus attention solely on the built objects, as I do in the case of appreciation (or unexpected disturbance). However, normally, these objects still 
appear to me (to some relatively minimal degree), directly-insofar as they are part of my extended attentional field, and indirectly-as a possibility for attention, through the others that I encounter. This greatly influences the construction of the experience that Benjamin defines as (habitual) distraction; ${ }^{72}$ therefore, it is involved in allowing human subjects in everyday urban environments to carry out simple familiar daily tasks while still attending to the environment.

The profound influence of the bodily presence of others on the subject's lived urban environment highlights the intimate relationship between the everyday experience of the built world and social attention. Specifically, it shows that attending to, and with others in everyday urban surroundings is significantly involved in the way built objects appear to the subject. This suggestion clarifies the crucial role of the bodily other in our lived urban world and helps to underscore the experiential structure of its everydayness.

\section{Notes}

1. Schutz, Collected Papers VI.

2. Ibid, 236 .

3. In this article, we name this phenomenon "everyday experience of the built environment."

4. Gurwitsch, Studies in Phenomenology and Psychology. Gurwitsch, Human Encounters in the Social World.

5. Schutz, The Phenomenology of the Social World. Collected papers VI. Gurwitsch, Studies in Phenomenology and Psychology; Human Encounters in the Social World.

6. Depraz, "Where is the Phenomenology of Attention that Husserl intended to Perform? A Transcendental Pragmatic-oriented Description of Attention." Gurwitsch, Studies in Phenomenology and Psychology.

7. Husserl, Ideas General Introduction to Pure Phenomenology, 246-250.

8. E.g. Lang et al., "Motivated Attention: Affect, Activation and Action"; Gallese \& Sinigaglia, "The Bodily Self as Power for Action."

9. W. Benjamin, "The Work of Art in the Age of Its Technological Reproducibility," 101-133.

10. Edward S. Casey explores the glance as a form of looking that by its own nature is distracted. He suggests "Distraction it may be in some significant sense; but if so, it is a distraction that adds to our knowledge of the world and does not merely detract from it." Casey, The World at a Glance, 300. Casey regards attention (or, better: "attending to," as opposed to focused attention) as the common sphere of human life: it is not that one remains in a constant state of focused attention, but rather that attention varies and can be divided between core, centralfocused attention (similar to Gurwitsch's thematic field) and marginal-peripheral attention.

11. Juhani Pallasmaa, advises his architectural colleagues to take into consideration the unfocused peripheral perception of users; this, he maintains, is the essential, dominant type of perception that impacts common human experience, as opposed to the thrilling experience derived from an encounter with monumental architecture. Pallasmaa, "Space, Place and Atmosphere. Emotion and Peripheral Perception in Architectural Experience," 230-245.

12. Casey, "Body, Self, and Landscape: A Geophilosophical Inquiry into the Place-World." Casey, Getting Back into Place, also expresses discomfort with the common approach to architecture as practice based largely on the sense of sight rather than fuller, sensorimotor, lived architectural experience. Pallasmaa adds that "the ocular bias... aimed at striking and memorable visual images ... [is mostly employed by the designers] instead of an existentially grounded plastic and spatial experience" (Pallasmaa, The Eyes of the Skin: Architecture and the Senses, 33). See also P. Zumthor, "A Way of Looking at Things." and Atmospheres: Architectural Environments - Surrounding Objects.); Böhme, "Atmosphere as the Subject Matter of Architecture," 398-406; and Leatherbarrow, Architecture Oriented Otherwise.

13. Merleau-Ponty, Phenomenology of Perception, 350. 
14. Gibson, The Ecological Approach to Visual Perception.

15. Casey, Getting Back into Place, 326-327.

16. Peri-Bader, "A Model for Everyday Experience of the Built Environment: The Embodied Perception of Architecture," 244-267.

17. See Gibson, The Ecological Approach to Visual Perception; Noë, Action in Perception; and Thompson, Mind in life: Biology, Phenomenology, and the Sciences of Mind, 383-386.

18. Gallagher \& Zahavi, The Phenomenological Mind: An Introduction to Philosophy of Mind and Cognitive Science, 89-103.

19. Ibid., 145.

20. As we show next, this occurs in different degrees of relatedness to the transient center of attention.

21. Depraz, "Where is the Phenomenology of Attention that Husserl intended to Perform? A Transcendental Pragmatic-oriented Description of Attention," 11-13.

22. Merleau-Ponty, Phenomenology of Perception, 31.

23. See Seamon, A Geography of the Lifeworld: Movement, Rest and Encounter and A. Haapala, "On the Aesthetics of the Everyday: Familiarity, Strangeness, and the Meaning of Place," 39-55.

24. See, for instance, Berleant, "On Getting Along Beautifully: Ideas for a Social Aesthetics," 12-29; and Berleant, "What is Aesthetic Engagement?".

25. Husserl, Ideas General Introduction to Pure Phenomenology, 248.

26. Gurwitsch, Studies in Phenomenology and Psychology, 203.

27. Following William James's notion in The Principles of Psychology, the prevalent accounts of attention in the psychological literature usually address attention as a limited and individualistic stimuli-driven process of focusing. See, for example, Lamy et al., "Selective Attention"; Chen, "Object-based Attention: a Tutorial Review"; Hoffman and Nelson, "Spatial Selectivity in Visual Search"; Posner, "Orienting of Attention"; Posner, Snyder, and Davidson "Attention and the Detection of Signals."

28. Gurwitsch, Studies in Phenomenology and Psychology, 218.

29. Ibid, 200.

30. Ibid, 201-202.

31. Ibid, 203.

32. Casey, "Body, Self, and Landscape: A Geophilosophical Inquiry into the Place-World."

33. See the detailed analysis in Peri-Bader, "A Model for Everyday Experience of the Built Environment," 244-267.

34. Gurwitsch, Studies in Phenomenology and Psychology, 206.

35. Ibid, 204.

36. Ibid, 205.

37. See Schutz's analysis of the structure of the social world: The Phenomenology of the Social World.

38. We distinguish between subjects' bodily know-how of everyday environments and their reliance on others as a source of relatedness or orientation to the built world. We argue that the bodily presence of others as social references extends the subject's attentional field and, importantly, influences the way the built world appears to him or her.

39. E.g., Brosch, "Neurocognitive Mechanisms of Attentional Prioritization in Social Interactions"; Tomasello, Why we Cooperate; Schilbach et al., "Toward a Second-Person Neuroscience." Zahavi, Husserl's Phenomenology; Zahavi, Self and Other: Exploring Subjectivity, Empathy, and Shame.

40. Rochat \& Striano, "Perceived Self in Infancy"; Rochat, "The Innate Sense of the Body Develops to Become a Public Affair by 2-3 Years"; Farroni et al., "Eye Contact Delectation in Humans from Birth"; Striano et al., "Eye Contact Influences Neural Processing of Emotional Expressions in 4-month-old Infants"; Peltola et al., "Emergence of Enhanced Attention to Fearful Faces between 5 and 7 Months of Age"; Hoehl \& Striano, "The Development of Emotional Face and Eye Gaze Processing."

41. Reddy, "A Gaze at Grips with Me." 
42. Butterworth, \& Jarrett, "What Minds have in Common is Space: Spatial Mechanisms serving Joint Visual Attention in Infancy"; Moore, \& Dunham, "Current Themes in Research on Joint Attention"; Carpenter et al., "Social Cognition, Joint Attention, and Communicative Competence from 9 to 15 Months of Age."

43. Tomasello, Why we Cooperate and Origins of Human Communication.

44. Walden \& Baxter, "The Effect of Context and Age on Social Referencing"; Klinnert et al., "Emotions as Behavior Regulators: Social Referencing in Infants."

45. Becchio et al., "Grasping Intentions: from Thought Experiments to Empirical Evidence."

46. Langton et al., "Do the Eyes have it? Cues to the Direction of Social Attention"; Yu \& Smith, "Joint Attention without Gaze Following: Human Infants and their Parents Coordinate Visual Attention to Objects through Eye-Hand Coordination."

47. Boothby et al., "Shared Experiences are Amplified"; Knoblich \& Sebanz "Evolving Intentions for Social Interaction: from Entrainment to Joint Action"; Shteynberg et al., "Feeling more Together: Group Attention Intensifies Emotion."

48. Birmingham, E. \& Kingstone, A., "Human Social Attention: A New Look at Past, Present and Future Investigations"; Schlibach et al., "Toward a Second-Person Neuroscience."

49. Gallese and Sinigaglia, "The Bodily Self as Power for Action"; Sinigaglia, "Enactive Understanding and Motor Intentionality"; Sinigaglia \& Rizzolatti, "Through the Looking Glass: Self and Others."

50. Husserl, The Crisis of European Sciences and Transcendental Phenomenology: An Introduction to Phenomenological Philosophy, 163.

51. Zahavi, Husserl and Transcendental Intersubjectivity: A Response to the Linguistic-Pragmatic Critique; Zahavi, Husserl's Phenomenology.

52. See also Sartre, Being and Nothingness.

53. Schutz, The Phenomenology of the Social World.

54. Ibid, 163.

55. Ibid, 142-143.

56. Ibid, 163.

57. Gurwitsch, Studies in Phenomenology and Psychology, 420.

58. Sartre, Being and Nothingness, 361-374.

59. Ibid, 367.

60. Ibid, 366.

61. Gurwitsch, Human Encounters in the Social World.

62. Gurwitsch, Studies in Phenomenology and Psychology.

63. E.g., Gallese \& Sinigaglia, "The Bodily Self as Power for Action"; Sinigaglia, "Enactive Understanding and Motor Intentionality."

64. Walden \& Baxter, "The Effect of Context and Age on Social Referencing"; Klinnert et al., "Emotions as Behavior Regulators: Social Referencing in Infants."

65. Schutz, The Phenomenology of the Social World, 168.

66. As we show next, in the absence of others the everydayness of my lived urban world breaks down.

67. Gurwitsch, Studies in Phenomenology and Psychology, 205.

68. Casey, Getting Back Into Place; Haapala "On the Aesthetics of the Everyday: Familiarity, Strangeness, and the Meaning of Place," 39-55.

69. Gallagher \& Zahavi, "Primal Impression and Enactive Perception."

70. Director: Cameron Crowe, USA and Spain, 2001.

71. Gurwitsch, Studies in Phenomenology and Psychology.

72. W. Benjamin, "The Work of Art in the Age of Its Technological Reproducibility."

\section{Acknowledgements}

We are grateful to Eva Jablonka and Dan Zahavi for useful comments and suggestions. We would also like to thank the Australian Association of Philosophy for inviting us to present an early version of this article at the AAP Conference 2015. 


\section{Disclosure statement}

No potential conflict of interest was reported by the authors.

\section{Notes on contributors}

Aya Peri Bader is an architect and a lecturer at David Azrieli School of Architecture, Tel Aviv University, where she is also writing her $\mathrm{PhD}$ dissertation on the ordinary and extraordinary experience of the built environment in everyday life. Her research interests include the phenomenology of the architectural experience, everyday aesthetics, and cinematography. Her work has been presented at a number of international conferences and published in the peer-reviewed journals Emotion, Space and Society, and The Journal of Architecture. Her book on the city and the port in the Israeli cinema (in Hebrew) will be published in 2017 by Resling Press.

Oren Bader, LL.B, is a PhD candidate at the Cohn Institute for the History and Philosophy of science and ideas, School of Philosophy, Tel Aviv University, under the supervision of Eva Jablonka (Tel Aviv University) and Dan Zahavi (University of Copenhagen). His research field is the evolution, development and phenomenological structure of human social attention. His research interests include social phenomenology, the philosophy of biology, the philosophy of cognitive science and the philosophy of mind. His work has been presented at a number conferences and published in the peer-reviewed journal Consciousness and Cognition and as a chapter in the forthcoming volume Landscapes of Collectivity in the Life Sciences (MIT Press, 2017).

\section{References}

Becchio, C., Manera, V., Sartori, L., Cavallo, A., \& Castiello, U. 2012. "Grasping Intentions: From Thought Experiments to Empirical Evidence," Frontiers in Human Neuroscience 6: 117.

Benjamin, W. 2002 [1936]. “The Work of Art in the Age of Its Technological Reproducibility," Second Version. In Jennings (ed) Walter Benjamin: Selected Writings, 3, 1935-1938, pp. 101-133. Cambridge: Harvard University Press.

Berleant, A. 2013. "What is Aesthetic Engagement?" Contemporary Aesthetics 11, accessed February 16, 2015, http://www.contempaesthetics.org/newvolume/pages/article.php?articleID=684

Berleant, A. 1999. "On Getting Along Beautifully: Ideas for a Social Aesthetics," In P. von Bonsdorff and A. Haapala (eds) Aesthetics in the Human Environment, pp. 12-29. Lahti: International Institute of Applied Aesthetics.

Birmingham, E. and Kingstone, A. 2009. "Human Social Attention: A New Look at past, Present and Future Investigations". The Year in Cognitive Neuroscience: Annals of the New York Academy of Sciences 1156: 118-140.

Böhme, G. 2005. "Atmosphere as the Subject Matter of Architecture". In P. Ursprung J. Herzog and P. de Meuron (eds). Natural Histories, pp. 398-405. Baden, Switzerland: Lars Müller Publishers.

Boothby, E. J., Clark, M. S., \& Bargh, J. A. 2014. "Shared Experiences Are Amplified," Psychological Science 25: 2209-2216.

Brosch, T. 2014. "Neurocognitive Mechanisms of Attentional Prioritization in Social Interactions." In C. Von Scheve and M. Salmela (eds) Collective Emotions, pp. 78-93. Oxford: Oxford University Press.

Butterworth, G. and Jarrett N. 1991. "What Minds Have in Common is Space: Spatial Mechanisms Serving Joint Visual Attention in Infancy," British Journal of Developmental Psychology 9: 55-72.

Carpenter, M., Nagell, K., \& Tomasello, M. 1998. "Social Cognition, Joint Attention, and Communicative Competence from 9 to 15 Months of Age," Monographs of the Society for Research in Child Development 63, 4 (Serial No. 255): 1-143.

Casey, E. S. 2001. "Body, Self, and Landscape: A Geophilosophical Inquiry into the Place-World." In P. Adams S. Hoelscher and K. Till (eds) Textures of Place: Exploring Humanist Geographies, pp. 403-419 Minneapolis, MN: University of Minnesota Press, 2001. 
Casey, E. S. 2007. The World at a Glance. Bloomington: Indiana University Press.

Casey, E. S. 2009. Getting Back into Place. Bloomington, IN: Indiana University Press.

Chen, Z. 2012. "Object-Based Attention: A Tutorial Review," Attention, Perception and Psychophysics 74: 784-802.

Depraz, N. 2004. "Where is the Phenomenology of Attention That Husserl Intended to Perform? A Transcendental Pragmatic-Oriented Description of Attention," Continental Philosophy Review 37: 5-20.

Farroni, T., Csibra, G., Simion, F., \& Johnson, M. H. 2002. "Eye Contact Delectation in Humans from Birth," Proceedings of the National Academy of Sciences 99: 9602-9605.

Gallagher, S. and Zahavi D. 2008. The Phenomenological Mind, an Introduction to Philosophy of Mind and Cognitive Science. New York and London: Routledge.

Gallagher, S. and Zahavi D. 2014. "Primal Impression and Enactive Perception," In V Arstila and D Lloyd (eds) Subjective Time: The Philosophy, Psychology, and Neuroscience of Temporality, pp. 83-99. Cambridge, MA: MIT Press.

Gallese, V. and Sinigaglia C. 2010. “The Bodily Self as Power for Action," Neuropsychologia 48: 746-755.

Gibson, J. J. 1986. The Ecological Approach to Visual Perception. Hillsdale, NJ: Lawrence Erlbaum Associates.

Gurwitsch, A. 1966. Studies in Phenomenology and Psychology. Evanston: Northwestern University Press.

Gurwitsch, A. 1979. Human Encounters in the Social World. Pittsburgh: Duquesne University Press.

Haapala, A. 2005. "On the Aesthetics of the Everyday: Familiarity, Strangeness, and the Meaning of Place," In A. Light and J. M. Smith (eds) The Aesthetics of Everyday Life, pp. 39-55. New York, NY: Columbia University Press.

Hoehl, S. and Striano T. 2010. "The Development of Emotional Face and Eye Gaze Processing," Developmental Science 13(6): 813-825.

Hoffman, J. E. and Nelson B. 1981. "Spatial Selectivity in Visual Search," Perception \& Psychophysics 30: 283-290.

Husserl, E. 1962 [1913]. Ideas General Introduction to Pure Phenomenology. W.R. Gibson-Boyce. New York, NY. Collier Books

Husserl, E. 1970 [1936]. The Crisis of European Sciences and Transcendental Phenomenology: An Introduction to Phenomenological Philosophy. D. Carr (introduction and translation), Evanston, IL: Northwestern University.

James, W. 1890. The Principles of Psychology. New York, NY: H. Holt and Company.

Klinnert, M. D., Campos, J. J., Sorce, J. F., Emde, R. N., \& Svejda, M. 1983. "Emotions as Behavior Regulators: Social Referencing in Infants," In R. Plutchik and H. Kellerman (eds) Emotion Theory, Research, and Experience. vol. 2. Emotions in Early Development, pp. 57-68. New York, NY: Academic Press.

Knoblich, G. and Sebanz N. 2008. "Evolving Intentions for Social Interaction: From Entrainment to Joint Action," Philosophical Transactions of the Royal Society, London. B: Biological Sciences 363(1499): 2021-2031.

Lamy, D., Leber, A. B. and Egeth, H. E. 2012. "Selective Attention," In A. F. Healy and R.W. Proctor (eds) Experimental Psychology. Volume 4 of the Comprehensive Handbook of Psychology, Fourth Edition, pp. 265-294. Editor-in-Chief: I. B. Weiner. New York, NY: Wiley.

Langton, S. R. H., Watt, R. J., \& Bruce, V. 2000. "Do the Eyes Have It? Cues to the Direction of Social Attention," Trends Cognit. Sci. 4, no. 2: 50-59.

Leatherbarrow, D. Architecture Oriented Otherwise. New York, NY: Princeton Architectural Press, 2009.

Merleau-Ponty, M. 1986 [1945] Phenomenology of Perception. Colin Smith (trans). New York: Routledge.

Moore, C. and Dunham P. J. 1995. "Current Themes in Research on Joint Attention," In C. Moore and P.J. Dunham (eds) Joint Attention: Its Origins and Role in Development, 15-28. Hillsdale, NJ: Lawrence Erlbaum.

Noë, A. 2004. Action in Perception. Cambridge, MA: MIT Press.

Pallasmaa, J. 2012. The Eyes of the Skin: Architecture and the Senses. Chichester: Wiley Academy. 
Pallasmaa, J. 2014. "Space, Place and Atmosphere. Emotion and Peripheral Perception in Architectural Experience," Lebenswelt - Aesthetics and Philosophy of Experience 4 (1): 230-245.

Peltola, M. J., Leppänen, J. M., Maki, S., \& Hietanen, J. K. 1997. "Motivated Attention: Affect, Activation and Action," In P. J. Lang, R. F. Simons and M. T. Balaban (eds) Attention and Orienting: Sensory and Motivational Processes, pp. 97-136, Hillsdale, NJ: Lawrence Erlbaum Associates, Inc.

Peltola, M. J., Leppänen, J. M., Maki, S., \& Hietanen, J. K. 2009. "Emergence of Enhanced Attention to Fearful Faces between 5 and 7 Months of Age," Social Cognitive and Affective Neuroscience 4: $134-142$.

Peri-Bader, A. 2015. "A Model for Everyday Experience of the Built Environment: The Embodied Perception of Architecture," The Journal of Architecture 20 (2): 244-267.

Posner, M. I. 1980. "Orienting of Attention," Quarterly Journal of Experimental Psychology 32: 3-25.

Posner, M. I., Snyder C. R. and Davidson B. J. 1980. "Attention and the Detection of Signals," Journal of Experimental Psychology: General 109: 160-174.

Reddy, V. 2012. "A Gaze at Grips with Me," In A. Seemann (ed.) Joint Attention: New Developments in Philosophy, Psychology, and Neuroscience, pp. 137-157.Cambridge, MA: MIT Press.

Rochat, P. 2010. "The Innate Sense of the Body Develops to Become a Public Affair by 2-3 Years," Neuropsychologia 48 (3): 738-745.

Rochat, P. and Striano T. 2001 "Perceived Self in Infancy," Infant Behavior and Development 23: 513-530.

Sartre, J. P. 2003 [1943]. Being and Nothingness. E.Hazel Barnes (trans) London: Routledge

Schilbach, L., Timmermans, B., Reddy, V., Costall, A., Bente, G., Schlicht, T., \& Vogeley, K. 2013. "Toward a Second-Person Neuroscience," Behavioral and Brain Sciences 36 (04): 393-414.

Schutz, A. 1967 [1932]. The Phenomenology of the Social World. G. Walsh (trans) Evanston, IL: Northwestern University Press.

Schutz A. 2013. Collected Papers VI. Literary Reality and Relationships Series: Phaenomenologica. 206. Barber Michael (ed) Dordrecht, Netherlands: Springer.

Seamon, D. 1979. A Geography of the Lifeworld: Movement, Rest and Encounter. London: Croom Helm Ltd.

Shteynberg, G., Hirsh, J. B., Apfelbaum, E. P., Larsen, J. T., Galinsky, A. D., \& Roese, N. J. 2014. “Feeling More Together: Group Attention Intensifies Emotion," Emotion. Advance online publication. http:// dx.doi.org/10.1037/a0037697

Sinigaglia, C., and Rizzolatti G. 2011. "Through the Looking Glass: Self and Others," Consciousness and Cognition 20: 64-74.

Sinigaglia, C. 2008. "Enactive Understanding and Motor Intentionality," In F. Morganti, et al. (eds) Enacting Intersubjectivity: A Cognitive and Social Perspective to Study of Interactions, 17-32. Amsterdam: IOS Press.

Striano, T., Kopp, F., Grossmann, T., \& Reid, V. M. 2006. “Eye Contact Influences Neural Processing of Emotional Expressions in 4-Month-Old Infants," Social Cognitive and Affective Neuroscience $1(2): 87-94$.

Thompson, E. 2007. Mind in Life: Biology, Phenomenology, and the Sciences of Mind. Cambridge, MA: Harvard University Press.

Tomasello, M. 2008. Origins of Human Communication. Cambridge, MA: MIT press.

Tomasello, M. 2009. Why We Cooperate. Cambridge, MA: MIT Press.

Walden, T. A. and Baxter A. 1989. "The Effect of Context and Age on Social Referencing," Child Development 60 (6): 1511-1518.

Yu, C. and Smith L. B. 2013. "Joint Attention without Gaze following: Human Infants and Their Parents Coordinate Visual Attention to Objects through Eye-Hand Coordination," PLoS ONE 8(11).

Zahavi, D. 2001. Husserl and Transcendental Intersubjectivity: A Response to the Linguistic-Pragmatic Critique. Athens, OH: Ohio University Press.

Zahavi, D. 2003. Husserl's Phenomenology. Stanford, CA: Stanford University Press.

Zahavi, D. 2014. Self and Other: Exploring Subjectivity, Empathy, and Shame. Oxford: Oxford University Press.

Zumthor, P. 1998. Thinking Architecture. Baden, Switzerland: Lars Müller.

Zumthor, P. 2006. Atmospheres: Architectural Environments - Surrounding Objects. Basel, Boston, Berlin: Birkhäuser. 